RU Теория эмпатии в анализе дискурса (на материале английского и французского языков)

\author{
Шевелева М. С.
}

\begin{abstract}
Аннотация. Цель исследования - обосновать релевантность теории эмпатии в определении прагмасемантики интерсубъектной коммуникации на примере диалогической и монологической речи бытового и художественного дискурса. В статье критически осмысливаются этапы становления теории эмпатии и ее интеграции в аналитический аппарат лингвистической науки. Описывается феномен первичной и вторичной эмпатии. Научная новизна исследования состоит в разработке моделей концептуализации и прагмасемантической интерпретации фрагментов дискурса с учетом фактора первичной и вторичной эмпатии. В результате доказана целесообразность включения компонента «слушающий» в концептуальную структуру диалогических и сверхфразовых единств франкоязычных и англоязычных текстов, так как подобный подход позволяет вскрыть глубинные механизмы, мотивирующие их семантическую репрезентацию и прагматическую модальность.
\end{abstract}

\title{
EN Theory of Empathy in Analysing Discourse (by the Material of the English and French Languages)
}

\section{Sheveleva M. S.}

\begin{abstract}
The purpose of the study is to substantiate relevance of the theory of empathy in determining pragmasemantics of intersubjective communication, using dialogic and monologic speech of everyday and literary discourses as an example. The article provides a critical insight into development stages of the theory of empathy and its integration into the analytical apparatus of linguistics. The phenomenon of first-order and second-order empathy is described. Scientific novelty of the work lies in developing models of conceptualisation and pragmasemantic interpretation of discourse fragments, taking into account the factor of first-order and second-order empathy. As a result, the researcher has proved usefulness of including the component "listener" in the conceptual structure of dialogic and super-phrasal unities of the English and French texts, since such an approach allows revealing deep mechanisms that motivate their semantic representation and pragmatic modality.
\end{abstract}

\section{Введение}

В современной лингвистике отмечается рост исследовательского интереса к аспектам межличностной коммуникации с позиций когнитивистики. Теория эмпатии, активно задействованная в нейрофизиологических, психологических и социальных исследованиях и впоследствии преобразованная в эффективный аналитический инструмент когнитивной лингвистики, психолингвистики и дискурс-анализа, предлагает большие возможности для осмысления прагматики и семантики вербальной интерсубъектной коммуникации.

В русле психологических и нейрофизиологических исследований под эмпатией понимается обусловленная наличием зеркальных нейронов в коре головного мозга способность человека имитировать, идентифицировать, адекватно интерпретировать и соотносить текущее эмоциональное состояние других людей со своим эмоциональным опытом. По сути, эмпатия в вышеупомянутых отраслях науки - это умение индивидуума посмотреть на ситуацию с точки зрения собеседника и вытекающие из данного умения принятие и понимание его актуального эмоционального состояния $[10 ; 17 ; 20 ; 23 ; 24 ; 27 ; 34 ; 36]$. Эмпатия также оценивается как осознанное деятельностное сопереживание эмоциональным реакциям другого, выраженное в том числе и через вербальную коммуникацию [30; 32].

Толкование термина «эмпатия», релевантное для настоящей работы, выстраивается с опорой на понимание эмпатии как явления вербальной коммуникации, предложенное учеными-лингвистами [11; 19; 25; 26; 31], 
и формулируется следующим образом. Эмпатия - это способ смысловой и прагматической организации информации, представленной в тексте, который реализуется за счет включения фактора говорящего и слушающего в аспекте их мировоззренческих позиций относительно обсуждаемого объекта и друг друга. Причем понимание эмпатии в данной работе исключает облигаторность наличия ярко выраженного эмоционального фона вербального интерсубъектного взаимодействия. Оно строится на способности коммуникантов воспринять, осмыслить и оценить информацию о каком-либо объекте или событии с опорой на общие фоновые и специфические знания и с учетом коммуникативных интенций друг друга. Выявление последних (в художественном тексте это оказывается возможным благодаря присутствию в его сюжетно-ролевой структуре авторского голоса, который либо принадлежит одному из персонажей, либо комментирует их реплики) позволяет определить специфику прагматической нагрузки высказываний собеседников и выделить языковые средства ее объективации.

Актуальность темы исследования обусловлена тем, что внедрение теории эмпатии в лингвистический анализ дает более глубокое понимание и возможность адекватной интерпретации (1) ментальных механизмов, управляющих процессами вербальной репрезентации информации в ходе интерсубъектного взаимодействия в бытовом и художественном дискурсе; (2) семиотической природы языка как способа хранения и переосмысления знаний и основного инструмента осуществления коммуникативной деятельности; (3) принципов прагматического оформления и смыслового наполнения диалогической и монологической речи в пространстве художественного литературного произведения.

Для достижения указанной цели исследования необходимо решить следующие задачи:

- уточнить интерпретацию термина «эмпатия» в лингвистике с учетом этапов развития и становления данной теории в гуманитарной науке в целом;

- представить и описать компоненты концептуальных схем первичной и вторичной эмпатии во взаимосвязи с модальностью высказывания;

- проанализировать посредством данных схем фрагменты диалогических и монологических художественных текстов;

- доказать, что концептуализация коммуникативной ситуации в художественном дискурсе через восприятие «говорящим» позиции «слушающего» способствует экспликации ее семантической и прагматической неоднозначности (амбигуентности), что повышает экспрессивность и смысловую насыщенность речевого произведения;

- продемонстрировать на примере анализа фактического материала посредством концептуальных схем первичной и вторичной эмпатии целесообразность и перспективность их включения в прагмасемантический анализ дискурса.

Для решения поставленных задач в статье используются следующие методы исследования: метод интерпретативного, концептуального, прагмасемантического и когнитивно-дискурсивного анализа.

Теоретической базой исследования послужили публикации отечественных и зарубежных авторов Д. Герэртса [25; 26], У. Чейфа [11; 19], Дж. Олвуда [13-15], С. Куно [31], М. М. Бахтина [2], Н. Д. Арутюновой [1], Н. Н. Болдырева [3], Л. А. Манерко [7], Е. Л. Туницкой [9] и других, в которых разрабатывается теория эмпатии в аспекте интерсубъектной коммуникации и диалогичности художественного текста.

Практическая значимость работы заключается в том, что полученные результаты могут использоваться в дальнейших исследованиях фактов вербальной межличностной коммуникации в различных модусах и видах дискурса, а также в курсах по теории коммуникации, когнитивной лингвистики, психолингвистики и дискурс-анализа.

\section{Основные аспекты теории эмпатии как релевантной методологии лингвистического анализа}

Теория эмпатии сформировалась в лоне феноменологической философии. Ее основу составлял так называемый феномен «вчувствования» (Einfühlung) - «способность переноситься в мир представлений другого человека, обусловливающая возможность его понимания», - определенный Иоганном Готфридом Гердером еще в XVIII веке [4] и изучавшийся целой плеядой философов с аналогичных позиций. В частности, Э. Гуссерль и Э. Штайн трактовали «вчувствование» как процесс познания человеком сознания другого человека [5; 12]. При этом Э. Гуссерль еще тогда указывал на интерсубъективность эмпатии. Аргументируя важность опыта интерсубъектного взаимодействия в нашем восприятии себя как объективно существующих субъектов, мыслитель отмечает, что «не только жизнь сознания отдельного Я есть замкнутое в себе поле опыта, которое следует пройти в последовательном феноменологическом опыте, но такова же и универсальная жизнь сознания, которая, выходя за пределы отдельного Я, соединяет любое Я с другим Я в действительной или возможной коммуникации» [5, с. 315].

Сложившееся в философии понимание эмпатии как переноса своего Я в опыт другого Я в современной психологии трактуется как когнитивная эмпатия [37]. Так, 3. Фрейд вводит данное понятие в психологический дискурс, определяя его как «бессознательную имитацию поведения взрослых ребенком, позволяющую ему осваивать нравственные нормы общества» [10, с. 167]. В аппарат социальной психологии термин «эмпатия» входит уже в значении «способность к сопереживанию», что подразумевает не только интеллектуальную идентификацию опыта другого применительно к себе, но и способность человека разделять связанные с этим опытом эмоции. Именно вокруг этого понятия впоследствии выстраивается теория эмпатии в области психологии. 
В дальнейшем теория эмпатии получила свое развитие во всех отраслях когнитивной науки благодаря исследованиям нейрофизиологов. Результатом изучения Дж. М. Фустером когнитивной деятельности животных стало следующее наблюдение: большинство животных демонстрируют эмоциональную реакцию на внешнее воздействие, и только высшие животные способны еще и на реакцию когнитивную [24]. В то же самое время появляются исследования так называемых «зеркальных нейронов» [34], а ученые, работающие в области теории сознания, подчеркивают важность понимания человеком своих интенций и состояний наряду с интенциями и состояниями других людей для развития социального познания [27; 30].

С. Барон-Коэн заявляет, что человеческий мозг обладает особой функцией, позволяющей адресанту и адресату сопрягать свои коммуникативные действия, настраиваться на мысли, чувства и намерения друг друга [17]. Ученый характеризует отмеченную им способность как естественную и врожденную, обеспечивающую возможность социального контакта [Ibidem, p. 3]. Согласно его точке зрения, довольно спорной, по мнению большинства ученых, сам процесс межличностного общения является вторичным и в значительной степени зависит от способности человека «войти» в психику собеседника, представить его мнение о себе, особенности его мировосприятия и подстроить свое поведение под конкретного собеседника [Ibidem, p. 28]. Подобная способность, по мнению ученого, развилась у человека в процессе эволюции.

Исследования эмпатии в области теории сознания позволили установить, что данный феномен обусловливает у человека такие виды деятельности, как помощь и просоциальное поведение [20; 36]. В свою очередь, недостаток эмпатии является причиной антисоциального поведения [32], которое достаточно ярко проявляется и на уровне интерсубъектного вербального взаимодействия. Помимо всего прочего, эмпатия также отвечает и за способность принимать решения [Ibidem].

Достижения нейрофизиологии, социальной и когнитивной психологии в лингвистическом аспекте изучения феномена эмпатии невозможно переоценить. Сформировавшиеся в их русле представления являются прямой проекцией в лингвистическую теорию эмпатии - интегративную концепцию, сложившуюся на стыке нескольких гуманитарных дисциплин и применяющуюся для изучения когнитивно-эмотивных процессов, воплощенных в языке и речи. Таким образом, когнитивная лингвистика, или, как определяет данное направление Л. А. Манерко, «когнитивно-коммуникативная лингвистика», объединяет многообразие подходов и теорий [7, с. 48], представляющих «понимание и изучение языка как средства познания мира, формирования и выражения мысли, хранения и организации знаний в человеческом сознании» [3, с. 14].

В лингвистической науке данное направление получило свое развитие благодаря У. Чейфу [11; 19], Дж. Олвуду [13-15] и Д. Эдвардсу [22]. Исследуя коммуникативное взаимодействие и дискурс, ученые ставят целью выявление и определение функциональных аспектов и сущности эмпатии как когнитивно-эмотивного феномена. Анализ различных аспектов актуализации дискурса является научным поиском доказательств воплощения процессов имитации, симуляции и репрезентации в речевой деятельности человека. Большинство работ, выполненных в рамках данного направления, - это попытка установить корреляции между языковой реализацией и функциональными аспектами эмпатии.

В рамках когнитивных лингвистических исследований, и в частности когнитивно-ориентированного дискурс-анализа, данный термин частично утрачивает отсылку к исключительно эмотивной составляющей речевого или акционального взаимодействия между людьми. В русле теории дискурса под эмпатией понимается способность говорящего смотреть на представленную в информационном событии ситуацию со стороны собеседника (участника/субъекта коммуникации) или референта (объекта коммуникации). Коммуниканты, или потребители какого-либо дискурса, отождествляют себя либо с собеседником, либо с референтом коммуникативной ситуации, т.е. «эмпатизируют» им. Тот объект или субъект коммуникации, с которым говорящий эмпатизирует, определяется У. Чейфом как «фокус эмпатии», а сама эмпатия представляет собой один из способов «упаковки информации» [11]. Как отмечает А. Л. Лось, теория эмпатии оказывается важной «для семантического описания единиц, ориентированных на языковую репрезентацию процессов восприятия» [6, с. 131].

Однако эмпатия в лингвистике - это не только способ «упаковки информации» [11] в бытовом или институциональном дискурсе. В лингвистическом анализе существует еще одно расширение понятия эмпатии, предложенное американским лингвистом С. Куно, - это «эмпатия говорящего» [31]. В отличие от других исследователей в области лингвистики он один из первых попытался выявить языковые средства реализации авторской эмпатии в художественном тексте, в очередной раз поставив вопрос о диалогичности художественного нарратива. С. Куно определяет данный аспект феномена эмпатии как «сюжетно-композиционный прием ведения авторского повествования с точки зрения персонажа» [9, с. 121].

Таким образом, сложившаяся на сегодняшний день лингвистическая трактовка данного явления обладает методологическим потенциалом и релевантностью в изучении интерсубъектной вербальной коммуникации и определении ее прагмасемантики в бытовом, персональном, институциональном и художественном дискурсе. Рассмотрим прикладные аспекты теории эмпатии в лингвистике более подробно.

\section{Особенности актуализации и концептуальная структура первичной и вторичной эмпатии}

В своем исследовании «Эмпатия как источник амбигуентности интерсубъектной коммуникации» Д. Герэртс предпринимает попытку разобраться в том, каким образом наша способность понимать точку зрения или отношение к какой-либо ситуации другого человека («эмпатия первого порядка») соотносится с так называемой 
«эмпатией второго порядка» [25, с. 12-13]. Эмпатия второго порядка - это способность коммуникантов осмыслить, каким образом собеседник концептуализирует свою точку зрения относительно их оценки ситуации, какова концептуальная структура, интегрированная в то или иное диалогическое единство, и каким образом она позволяет раскрыть отношение говорящих не только к предмету разговора, но и к тому, как они сами воспринимают и интерпретируют реакцию друг друга на высказанную оценку ситуации. То есть эмпатия второго порядка - это настроенность «говорящего» не только на оценку «слушающим» обсуждаемого объекта или ситуации, но и на его восприятие точки зрения говорящего.

Эмпатия и первого, и второго порядка оказывает значительное влияние на статус общего знания как фактора, обеспечивающего адекватность и прагматику интерсубъектного речевого взаимодействия. Так, понятие эмпатической интерпретации указывает на необходимость включения собеседника как независимого концептуализатора в интерсубъектную модель общего знания коммуникативной ситуации. Это, в свою очередь, предоставляет интерпретатору возможность выбора ракурса эмпатии первого порядка (что думает собеседник об обсуждаемой ситуации) или эмпатии второго порядка (что думает собеседник о том, что думаю я об обсуждаемой ситуации) в ходе толкования высказываний коммуникантов и может повлечь за собой не поддающуюся упрощению и преобразованию амбигуентность семантики и прагматики высказывания на уровне концептуального базиса.

Следует оговориться, что термин амбигуентность (ambiguity) заимствован из английского языка и означает "a word or expression that can be understood in two or more possible ways" [29] / «слово или выражение, которые могут иметь два толкования и более»; “а situation or statement that is unclear because it can be understood in more than one way” [28] / «неоднозначная ситуация или утверждение, смысл которых может интерпретироваться двумя или более способами» и тому подобное (здесь и далее перевод автора статьи. - М. Ш.).

В частности, Д. Берри с соавторами в своем труде, посвященном амбигуентности в лингвистическом понимании, выделяет (1) лексический, (2) семантический, (3) синтаксический и (4) прагматический типы лингвистической неоднозначности (ambiguity/амбигуентности) [18]. С точки зрения исследователей, лексическая амбигуентность обусловлена такими явлениями, как омонимия и полисемия, семантическая - вызвана отсутствием разрешающего контекста, синтаксическая неоднозначность - «двунаправленным референциальным вектором, когда один и тот же атрибут может быть отнесен к двум различным объектам/субъектам». Прагматическая амбигуентность, или прагматическая неоднозначность, «возникает, когда грамматически и лексически однозначное высказывание может быть интерпретировано по-разному участниками диалогического общения» [8, с. 83].

Под амбигуентностью в данном исследовании понимается прагмасемантическая неоднозначность высказывания, обусловленная (1) отсутствием у говорящего и слушающего достаточного объема знаний для формирования согласованной точки зрения на объект коммуникации и (2) несоответствиями в восприятии ими взглядов друг друга на данный объект в силу различий их индивидуальных установок, личностных и социокультурных характеристик. Если говорить об амбигуентности высказывания, то в этом случае одно и то же высказывание может интерпретироваться по-разному в зависимости от установок слушающего относительно того, как оценивается говорящим его точка зрения на объект коммуникации (определенную ситуацию или проблему). Таким образом, фактор первичной и вторичной эмпатии обусловливает множественность интерпретаций прагматики фрагментов дискурса, а амбигуентность, обусловленная эмпатией второго порядка, может погашаться лишь при условии экспликации оценки слушающим того, что думает о его мнении говорящий.

Концептуальные схемы, репрезентирующие различные модели интерсубъектной коммуникации с учетом первичной и вторичной эмпатии, включают такие составляющие, как «говорящий» - S (Self), «слушающий»O (Other), «объект коммуникации», обсуждаемая ситуация - (p). Разные позиции говорящего и слушающего относительно объекта коммуникации (первичная эмпатия) или их мнение о мнении собеседника об объекте коммуникации (вторичная коммуникация) порождают вариантность прагматической актуализации фрагментов дискурса.

Необходимо также подчеркнуть, что концептуальная структура интерсубъектной коммуникации с учетом первичной и вторичной эмпатии строится с использованием глаголов «полагает» и «утверждает», поскольку (исходя из рабочего определения эмпатии, предложенного в рамках настоящего исследования) данное явление рассматривается нами прежде всего как когнитивный механизм декодирования информационной структуры коммуникативного акта, в котором эмоциональная составляющая носит факультативный характер.

Если разрешение неоднозначности и множественной интерпретации не происходит на контекстуальном уровне, адресат высказывания систематически сталкивается с проблемой амбигуентности. Это вынуждает его задаваться вопросом, настроен ли собеседник на его реакцию и учитывает ли его точку зрения при интерпретации какого-либо факта объективной действительности, т.е. имеет ли место в их взаимодействии когнитивная эмпатия. Размытость прагмасемантических характеристик высказывания конкретизируется, если в нем присутствуют дейктические элементы. Например, темпоральный дейксис:

- So, the conference starts at 10 a.m.

- Exactly.

- Is it Moscow time or Brussels time?

- Moscow time, I think.

- So do I [26]. /

- Итак, конференция начинается в 10 утра.

- Точно. 
- По московскому или брюссельскому времени?

- Думаю, по московскому.

- Ия так думаю.

На уровне эмпатии первого порядка данное диалогическое единство концептуализируется как $\mathbf{S}$ полагает, что 0 полагает, что $\mathbf{p} \rightarrow \mathbf{O}$ утверждает, что $\mathbf{p}$, из чего можно вывести, что прагматическая модальность определяется как положительное утверждение, поскольку коммуниканты демонстрируют одинаковый объем знаний относительно времени начала конференции (p - событие, являющееся объектом коммуникации). Тогда как на уровне эмпатии второго порядка данный фрагмент дискурса может концептуализироваться как $\mathbf{S}$ полагает, что $O$ полагает $\mathbf{p}$ и $S$ полагает, что $O$ полагает, что $S$ полагает, что $\mathbf{p} \rightarrow$ O утверждает, что p. B этом случае в фокусе оказывается не информированность говорящего и слушающего относительно объекта коммуникации, а их настроенность на мнение друг друга, которое, исходя из согласованности их оценок, выраженных в высказываниях Exactly и So do I, определяется как согласие. Таким образом, на уровне вторичной эмпатии языковыми средствами, снимающими вопросы о прагматической модальности данного диалогического единства, оказываются не только темпоральные дейктические единицы, но и высказывания Exactly и So do I, подтверждающие, что оценивание времени начала конференции (р) происходит с общих для коммуникантов позиций.

В следующем примере амбигуентным оказывается весь диалог:

- How is my new car (paper, house, etc.)?

- Amazing [Ibidem]! /

- Как тебе моя новая машина (статья, дом и т.n.)?

- Потрясающе!

В качестве языковых средств, позволяющих определить информационную структуру и прагматику рассматриваемого фрагмента дискурса, выступает ответ слушающего (0) - Amazing!, содержащий оценку объекта коммуникации р (car, paper, house, etc. - машина, статья, дом и m.n.). Соответственно, прагматическая амбигуентность данного примера разрешается посредством семантики лексической единицы amazing.

Уровень эмпатии первого порядка данного диалога так же, как и в предыдущем примере, формируется вокруг объекта коммуникации и соотносится со схемой $\mathbf{S}$ полагает, что $\mathbf{O}$ полагает, что $\mathbf{p} \rightarrow \mathbf{O}$ утверждает, что p, которая концептуализирует включенность коммуникантов в общее знание относительно объекта коммуникации, который оценивается ими как amazing.

На уровне эмпатии второго порядка анализируемый фрагмент дискурса может обрести смысловую и прагматическую ясность при условии включения в него следующего вопроса: Do you really think so or do you say this just to please me (to spare my feelings / to avoid confrontation, etc.) [Ibidem]? / Ты действительно так думаешь или говоришь это, чтобы сделать мне приятно (не обидеть меня / избежать конфликта и т.п.)? Однако подобный вопрос далеко не всегда озвучивается говорящим в ситуации реального общения. Из-за этого могут возникнуть как минимум три интерпретации в зависимости от того, что думают участники диалога по поводу обсуждаемого предмета и насколько верно говорящий «считывает» мнение слушающего. Например, если, обмениваясь мнениями, оба участника искренне оценивают обсуждаемый предмет как Amazing! и если они убеждены в искренности друг друга, то концептуальная схема $\mathbf{S}$ полагает, что $\mathbf{O}$ полагает $\mathbf{p}$ и $\mathbf{S}$ полагает, что $\mathbf{O}$ полагает, что $S$ полагает, что $\mathbf{p} \rightarrow \mathbf{O}$ утверждает, что $\mathbf{p}$ соотносится с модальностью согласия. Если же исход данной схемы другой - S полагает, что O полагает р и $\mathbf{S}$ полагает, что О полагает, что $\mathbf{S}$ полагает, что $\mathbf{p} \rightarrow$ О утверждает, что -p (слушающий, отзываясь о предмете вопроса и используя определение Amazing!, на самом деле так не думает), тогда прагматическая модальность данного коммуникативного акта является либо иронической, либо неискренней, притворной, а возможно, и издевательской.

При концептуализации данного диалога посредством схемы $\mathbf{S}$ полагает, что $\mathbf{O}$ полагает $\mathbf{p}$ и $\mathbf{S}$ полагает, что $\mathrm{O}$ полагает, что $\mathrm{S}$ полагает, что $-\mathbf{p} \rightarrow \mathbf{O}$ утверждает, что $\mathbf{p}$, т.е. когда отвечающий на вопрос говорит Amazing!, будучи убежденным, что спрашивающий вовсе невысокого мнения о своей машине, статье и т.п., имеет место намеренный обман собеседника, причина которого может быть установлена с помощью контекста. Так, отвечающий может сказать неправду, чтобы сделать комплимент, польстить или не ранить чувства своего собеседника. Соответственно, прагматическая модальность диалога в такой интерпретации - это комплимент, лесть или компромисс.

Таким образом, эмпатия второго порядка запускает потенциальную множественность толкований фрагментов дискурса (амбигуентность), которые в зависимости от перспективы организации и восприятия информации коммуникантами могут определяться как согласие, обман, уступка/компромисс и ирония.

\section{Первичная и вторичная эмпатия в художественном дискурсе}

В исследовании Д. Герэртса эмпатия второго порядка как источник амбигуентности в межличностном общении рассматривается на примере обыденной коммуникации, тогда как художественный дискурс может предложить гораздо более широкое понимание диалогичности и интерсубъектности, нежели дискурс бытовой или институциональный.

Диалогичность художественного текста отмечалась еще М. М. Бахтиным [2] и Н. Д. Арутюновой [1], поскольку данная разновидность текста, представляя собой прозаический сюжетный дискурс, актуализирует и взаимоотношения, складывающиеся между персонажами художественного литературного произведения, и между 
автором и читателем «с учётом ситуации создания данного произведения и ситуации его прочтения» [9, с. 120]. Е. Л. Туницкая также указывает на релевантность теории эмпатии в исследовании прагматики художественного текста. Как отмечает исследователь, литературное произведение представляет собой «вымышленный мир, “населенный” персонажами - носителями собственной точки зрения, которые наделены собственным взглядом на описываемые события, как на уровне информированности о них (знание/незнание), так и на эмоционально-оценочном и идеологическом уровне» [Там же].

Включение фактора эмпатии второго порядка (посредством добавления в концептуальную схему концептуализатора «слушающий») в анализ диалогических единств позволяет более полно раскрыть возможные интенции участников разговора и точнее определить его модальность. Этому также способствует и то, что в некоторых текстовых фрагментах, помимо реплик героев-коммуникантов, обнаруживаются еще и авторские комментарии, проливающие свет на пресуппозициональный фон всего коммуникативного события.

Рассмотрим на примере анализа фрагментов франкоязычных и англоязычных художественных текстов, каким образом может работать данная методология применительно к диалогической речи в художественном тексте.

В первой части диалога, взятого из романа Э. Шмитта «Мечтательница», фраза героя (S), объясняющего свой вопрос о предполагаемых писательских притязаниях и талантах (р) Эммы (0), интерпретируется на уровне первичной эмпатии как ошибка $-\mathbf{S}$ полагает, что $\mathbf{O}$ полагает, что $\mathbf{p} \rightarrow \mathbf{O}$ утверждает, что -p, тогда как обмен репликами во второй части беседы, где Эмма определяется как говорящий (S), может быть концептуализирована схемой вторичной эмпатии - S полагает, что O полагает $\mathbf{p}$ и $\mathbf{S}$ полагает, что $\mathbf{O}$ полагает, что $S$ полагает, что $\mathbf{p} \rightarrow$ O утверждает, что $-\mathbf{p :}$

Nous retournâmes au salon avec la théière et d'autres biscuits.

- Écrivez-vous, Emma?

- Pourquoi cette question? Tout le monde me la pose!

- Vous lisez tellement.

- I'ai commis quelques épouvantables poèmes mais je vais m'arrêter là. Lire et écrire, ça n'a aucun rapport.

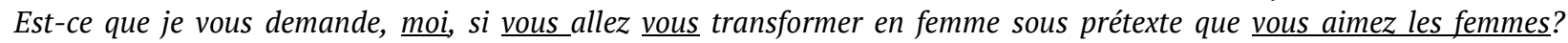
Eh bien, votre question est aussi absurde.

- C'est juste, mais comment savez-vous que j'aime les femmes [35, p. 19]? / Мы вернулись в гостиную с чайником и второй порцией бисквитов.

- Скажите, Эмма, а вы сами пишете?

- Почему вы спросили? Странно, все задают мне этот вопрос!

- Вы ведь столько читаете.

- Я сочинила несколько ужасных стихов, но думаю, что на этом и остановлюсь. Чтение и сочинительство не имеют между собой ничего общего. Это все равно, что я спросила бы вас, не хотите ли вы превратиться в женщину лишь потому, что любите женщин! Ну вот, ваш вопрос звучит также абсурдно.

- Это верно, но откуда вы взяли, что я люблю женщин?

Эмма сама конструирует ситуацию, в которой пытается предугадать реакцию своего собеседника (0) на ее утверждение о том, что он любит женщин (р). В данном примере вторичная эмпатия актуализируется в диалоге героев за счет последней, довольно обескураживающей реплики молодого писателя (C'est juste, mais comment savez-vous que j'aime les femmes?), единиц персонального дейксиса (vous; je; тоі) и лексики, объективирующей объект коммуникации (vous aimez les femmes / j'aime les femmes). Вопрос, заданный собеседником Эммы, сообщает данному коммуникативному акту прагматический эффект ироничности и провокативности, поскольку собеседник Эммы (0) намекает, что ее предположение может быть ошибочным, но в его реплике нет полной определенности.

В отрывке из автобиографичного романа К. Болдинг «Мои животные и другая семья» представлен диалог маленькой Клэр с отцом:

He once made me beans on toast.

'This will be the best beans on toast you have ever had,' he said as he covered the toast on a layer of butter.

'Mmmm,' I said, wanting him to know how much I appreciated it.

'Isn't that good? Doesn't it taste yummy? Is it the best meal you've ever had?'

'Yeth' - my mouth was full - ith the beth'd ever.'

For weeks, my father talked about having given me the most delicious meal I had ever had. He did the same with the dogs. <...> He did this with concentration, the effort and the chaos of Michelin chef. $<\ldots>$ As he put down their bowls, he told each dog how lucky he or she was to have such a special meal, made by him [16, p. 41-42]. I

Однажды он сделал мне тост с бобами. «Это будет самый лучший тост в твоей жизни», - сказал он, намазывая масло на хлеб. «Мммм», - сказала я. Мне так хотелось, чтобы он понял, как я ему благодарна. «Ну что, хорошо? Правда, вкуснятина? Разве это не самая лучшая еда в твоей жизни?» «Да!» - кивала я с набитым ртом. «Самая лучшая».

Неделями мой отеи рассказывал всем подряд, как он накормил меня самой вкусной едой в моей жизни. То же самое он делал и для собак. <...> Он готовил им еду с сосредоточенностью, старанием и суетливостью шефповара мишленовского ресторана. <... Когда он раскладывал приготовленное по мискам, он сообщал каждой собаке, как невероятно ей повезло получить от него такую вкусную еду.

В данном отрывке первая часть - диалог Клэр (0) с отцом (S) о самой вкусной в мире еде (p) - может быть концептуализирована схемой эмпатии первого порядка $\mathbf{S}$ полагает, что $\mathbf{O}$ полагает, что $\mathbf{p} \rightarrow \mathbf{O}$ утверждает, 
что p, которая указывает на согласие Клэр с мнением отца (положительное утверждение). На это указывают определенные реплики персонажей: настойчивые вопросы отца, по сути, подталкивающие дочь к утвердительному ответу (Isn't that good? Doesn't it taste yummy? Is it the best meal you've ever had?), и утвердительные ответы Клэр (Mmmm. Yeth... ith the beth'd ever). Соответственно, первичная эмпатия актуализируется в данном диалоге на уровне высказываний говорящего и слушающего.

Однако по мере дальнейшего продвижения диалога уже в размышлениях автора, стоящего за маленькой Клэр (0), происходит активация уровня вторичной эмпатии - $\mathbf{S}$ полагает, что О полагает $\mathbf{p}$ и $\mathbf{S}$ полагает, что $\mathbf{O}$ полагает, что $\mathbf{S}$ полагает, что $\mathbf{p} \rightarrow \mathbf{O}$ утверждает, что -p. Здесь за информирующими, стилистически нейтральными, высказываниями (He once made me beans on toast / For weeks, my father talked about having given me the most delicious meal I had ever had / He did the same with the dogs) просматривается ироничный упрек взрослой дочери, адресованный отцу. Объективация компонентов концептуальной схемы высказывания в данном случае происходит на уровне лексики, репрезентирующей ситуацию, являющуюся объектом коммуникации (р), - мимолетная забота о ребенке (beans on toast / delicious meal), которая еще больше обесценивается в противопоставлении уходу за собаками (special meal) с учетом темпорального дейксиса. Так, дейктик опсе указывает на единичность ситуации, в которой достаточно долго упоминалось отцом (for weeks). Проблема амбигуентности вторичной эмпатии разрешается в данном тексте и за счет лексики, описывающей, как отец заботился о собаках (with concentration, the effort and the chaos of Michelin chef), что еще больше выделяет разнонаправленность мнений говорящего (отца) и слушающего (Клэр) о ситуации и понимания говорящим истинного настроя слушающего. В данном примере прагматическая неоднозначность текста проясняется прежде всего благодаря авторской эмпатии.

Так, по мнению Е. Л. Туницкой, авторская эмпатия реализуется через комплекс лингвистических средств, включающих дейктические единицы с пространственной и темпоральной семантикой, которые «функционально призваны соотносить описываемый факт с говорящим субъектом; образно говоря, они помещают говорящего в определённую точку наблюдения» [9, с. 125]. Данная точка зрения подтверждается анализом рассмотренного примера, поскольку именно в силу того, что автор меняет ракурс наблюдения за «говорящим» (Self), становится возможной интерпретация соответствующего фрагмента художественного дискурса на уровне вторичной эмпатии и выявления глубинных слоев его семантической репрезентации и прагматической модальности.

Интерактивность художественного нарратива проявляется не только на уровне интерсубъектного взаимодействия персонажей, но и на уровне взаимодействия автора и читателя и автора и персонажа/персонажей. В ряде случаев авторское повествование содержит обращение к читателю, в котором эксплицитно или имплицитно представлена не только точка зрения обеих сторон, но и то, что думает автор по поводу того, что думает читатель, и наоборот. Что касается взаимодействия автора и персонажей произведения, то оно экстериоризируется через авторскую оценку действий, поведения, отношения к чему-либо участников описываемых в произведении событий: приводится внутренний монолог героя, в котором реконструируется разговор с другими персонажами, комментируются отношения с другими участниками повествования и т.п.

Так, размышления героини романа Г. Делакура «Список моих желаний» Жослин содержат не только перечисление желаний ее мужа. На имплицитном уровне - это диалог с супругом, в котором Жослин дает оценку и их отношениям, и своему месту в них, высказывая мысли о том, что думает о ней ее муж: Il travaille chez Häagen-Dazs depuis l'ouverture de l'usine, en 1990. Il gagne deux mille quatre cents euros par mois. Il rêve d'un écran plat à la place de notre vieux poste Radiola. D’une Porsche Cayenne. D’une cheminée dans le salon. De la collection complète des James Bond en DVD. D’un chronographe Seiko. Et d'une femme plus belle et plus jeune que moi; mais ça il ne me le dit pas [21, p. 10]. / Жо paбoтает на заводе компании «Хааген-Дац» с самого его открытия, с 1990 года. Получает 2400 евро в месяи. Мечтает вместо нашего старенького телевизора марки «Радиола» купить плазменную панель. Мечтает о «порше-кайене». О камине в гостиной. О полной коллекции фильмов про Джеймса Бонда на DVD. О хронометре «Сейко». И о жене, более молодой и более красивой, чем я, - вот только в этом он мне не признается.

Учитывая знания Жослин (S) о желаниях ее мужа (0), в особенности о желании обзавестись более красивой и молодой женой (p), а также имея информацию о том, что он ей об этом не говорит, а она с ним это не обсуждает, можно предположить, что оба притворяются - они как бы «сговорились» делать вид, что все хорошо. При таких условиях данный текстовый фрагмент можно концептуализировать схемой эмпатии второго порядка - S полагает, что 0 полагает $\mathbf{p}$ и $\mathbf{S}$ полагает, что 0 полагает, что $\mathbf{S}$ полагает, что $\mathbf{p} \rightarrow$ О утверждает, что -p, которая экстериоризирует некую негласную договоренность между сторонами, притворство, возможно даже и ироничное отношение обоих к данной ситуации. Однако в том случае, когда супруг Жослин (0) не догадывается о том, что она в курсе его желаний (p), и утверждает обратное (вероятность подобного исхода можно уточнить, лишь обратившись к более широкому контексту романа), прагмасемантика такого текста вскрывается концептуальной схемой вторичной эмпатии - S полагает, что $\mathbf{O}$ полагает $\mathbf{p}$ и $\mathbf{S}$ полагает, что $O$ полагает, что S полагает, что -p $\rightarrow$ O утверждает, что -p - и определяется как обман. На лингвистическом уровне составляющие концептуальных схем вторичной эмпатии объективируются посредством информирующих высказываний, оформленных в виде списка (сходство со списком достигается за счет парцелляции, анафоры и параллелизма) и эксплицирующих желания Жо (мужа Жослин, который к тому же является и ее тезкой). В изложении Жослин данный список приобретает диалогичность и ироничность. Диалогичность обусловлена тем, что повествование ведется от лица Жослин, а ироничность обусловлена не только разнонаправленностью векторов восприятия брака супругами, отраженной в концептуальных схемах, но также включением в список вожделенных материальных объектов новой, более молодой и красивой жены (d'une femme plus belle et plus jeune que moi). Такая организация информации, с одной стороны, обесценивает статус жены, которая приравнивается к вещи, а с другой - характеризует Жо как человека исключительно меркантильного. 
Аналогичная двойственность присуща и интерпретации внутреннего монолога главной героини Джойс из новеллы канадской писательницы Э. Манро «Вымысел». В данном отрывке, представленном через нарратив всезнающего автора, разворачивается, по сути, диалог между Джойс и ее мужем Йоном, который оставил свою утонченную красавицу-жену ради малообразованной алкоголички Эди, работавшей у него помощницей:

How could this have happened? Joyce asks it of Jon and of herself and then of others. A heavy-striding heavy-witted carpenter's apprentice in baggy pants and flannel shirts and - as long as the winter lasted - a dull thick sweater flecked with sawdust. A mind that plods inexorably from one cliché or foolishness to the next and proclaims every step of the journey to be the law of the land. Such a person has eclipsed Joyce with her long legs and slim waist and long silky braid of dark hair. Her wit and her music and the second-higest IQ [33, p. 38]. / Как это могло случиться? Джойс спрашивала у Йона, у себя, у всех вокруг. Какая-то неповоротливая, туповатая помощница столяра в мешковатых джинсах и фланелевых рубашках, на которые она зимой натягивала скучный толстый, весь в опилках, свитер, изрекающая сплошные банальности и глупости, объявляющая тривиальные события, происходящие в ее жизни, законами мироздания, смогла затмить Джойс. Джойс с длинными ногами, тонкой талией и темной копной шелковистых волос. Изысканную интеллектуалку Джойс с ее талантом к музыке и одним из самых высоких IQ в школе.

Прагматическая амбигуентность и семантический объем данного текста, помимо включения фактора вторичной эмпатии, обусловлены еще и разнонаправленностью информации о сложившемся любовном треугольнике и возможностью изменения концептуального статуса участников коммуникации. Так, в качестве говорящего может рассматриваться Джойс (S), а в роли слушающего выступает Йон (0), объектом коммуникации является Эди (p), которая, с точки зрения Джойс, никак не могла заинтересовать ее мужа. Однако убежденность Джойс в том, что ее супруг разделяет ее мнение относительно Эди, погашается его отрицанием расставанием с Джойс ради Эди. При такой объективации компонентов концептуальной схемы вторичной эмпатии $S$ полагает, что $O$ полагает р и $S$ полагает, что O полагает, что S полагает, что $\mathbf{p} \rightarrow \mathbf{O}$ утверждает, что -p, прагматика скрытого в нарративе диалога оценивается как притворство. В том случае, если и говорящим (S), и объектом коммуникации (p) является Джойс, а Йон так и остается слушающим (0), прагматика данного текста определяется как ироничная, причем речь идет о самоиронии Джойс, которая транслируется всезнающим автором и выражается через лексические (включение в список качеств героини результата теста на IQ) и синтаксические средства (парцелляция). Таким образом, в отличие от примера из французской прозы концептуальная структура рассматриваемого высказывания объективируется одной и той же схемой, в которой совмещается прагматика притворства и иронии за счет различного фокуса эмпатии. Представленные выше варианты интерпретации прагматики данного текста не являются взаимоисключающими, что придает всему высказыванию дополнительный смысловой объем и парадоксальность.

Таким образом, как показывает анализ актуализации базовых концептуальных условий первичной и вторичной эмпатии, применение данной теории является одинаково релевантным для изучения прагмасемантики франкоязычного и англоязычного художественного текста. Однако сопоставление текстов, созданных в различных языковых культурах, неизбежно ведет к необходимости выявления и включения более тонких дифференцирующих культурно-специфичных и сюжетно-обусловленных характеристик в когнитивный профиль компонентов «говорящий», «слушающий» и «объект коммуникации», а также определения языковых средств, объективирующих концептуальные условия реализации эмпатии.

\section{Заключение}

Эмпатия, будучи ментальным явлением, непосредственно связанным со способностью человека к восприятию окружающего мира и взаимодействию с другими людьми, в том числе и посредством вербальной коммуникации, обладает чертами экстралингвистического и лингвистического феномена. Как феномен познания и отношения, она воплощается в вербальном межличностном взаимодействии через определенные лингвистические средства, к которым, как показал анализ примеров обыденного и художественного дискурсов, относятся дейктические знаки, лексические единицы, объективирующие характеристики участников информационного события (говорящего, слушающего и объекта коммуникации), и определенные типы высказываний.

Общие фоновые знания воплощают концептуальную опору, обеспечивающую возможность межличностного взаимодействия в ходе вербальной коммуникации. Однако, как показывает проведенное исследование, основанное на концепции, предложенной Д. Герэртсом [25; 26], обусловленная эмпатией амбигуентность модальности и прагматики высказываний в каком-то смысле подрывает этот фундамент, и он оказывается довольно неустойчивым и уязвимым. Включение в теорию эмпатии концептуализатора «слушающий» обеспечивает возможность более точной интерпретации концептуальной основы речевого взаимодействия, особенно в аспекте способности слушающего оценивать точку зрения говорящего.

Выбор ракурса первичной или вторичной эмпатии, который предоставляется интерпретатору для оценки высказывания говорящего, вводит принцип взаимообусловленности межсубъектной интеракции, а субъективация автора в художественном тексте позволяет рассматривать даже формально монологический текст как вариант интерсубъектной коммуникации и инкорпорировать в прагмасемантический анализ художественного нарратива концептуализатор «слушающий» (других персонажей, за которыми может стоять автор) через отношение говорящего (всезнающий автор или внутренний наблюдатель) к его точке зрения на объект коммуникации. Внедрение концептуализатора «слушающий» в интерпретацию прагматики и семантики диалогов и авторских монологов в художественном литературном пространстве значительно обогащает смысловую 
и информационную нагрузку произведения в перспективе читателя, наполняет «возможный мир», созданный автором, дополнительным объемом и красками.

Перспективы дальнейшего исследования видятся в выявлении, систематизации и сопоставлении сюжетно и культурно обусловленных параметров составляющих концептуальных схем первичной и вторичной эмпатии на уровне объективации соответствующим художественным текстом. Это будет способствовать не только более глубокому осмыслению вопросов межличностной и межкультурной коммуникации на примере ситуаций объективной действительности, воссозданной в художественном тексте, но и дальнейшему развитию теории эмпатии в лингвистике.

\section{Список источников}

1. Арутюнова Н. Д. Типы языковых значений. Оценка, событие, факт. М.: Наука, 1988. 338 с.

2. Бахтин М. М. Слово в романе. М.: Пальмира, 2017. 229 с.

3. Болдырев Н. Н. Когнитивная семантика: введение в когнитивную лингвистику. Тамбов: ИД ТГУ им. Г. Р. Державина, 2014. 236 с.

4. Вчувствование [Электронный ресурс] // Философский словарь. URL: http://www.harc.ru/slovar/420.html (дата обращения: 25.10.2020).

5. Гуссерль Э. Избранные работы. М.: Территория будущего, 2005. 464 с.

6. Лось А. Л. Средства выражения эмпатии в языке // Филологические науки. Вопросы теории и практики. 2014. № 10 (40). Ч. 1. С. 131-135.

7. Манерко Л. А. Что дала психологическая наука когнитивной лингвистике // Методологические основы исследования когниции и коммуникации в современной лингвистике. М.: МАКС Пресс, 2017. С. 42-51.

8. Сергеева Ю. М. Фактор адресата как причина амбигуентности диалогического дискурса // Актуальные вопросы лингвистики и лингводидактики: традиции и инновации: в 2-х ч. М.: МПГУ, 2018. Ч. 1. С. 81-87.

9. Туницкая Е. Л. Лингвистические маркеры персонажа - объекта авторской эмпатии // Филологические науки в МГИМО. 2019. № 1 (17). С. 120-127.

10. Цветкова О. И. Эмпатия как профессиональная характеристика в деятельности психолога дошкольного учреждения: дисс. ... к. психол. н. Тверь, 1997. 208 с.

11. Чейф У. Данное, контрастивность, определенность, подлежащее, топики и точка зрения // Новое в зарубежной лингвистике. М.: Наука, 1982. Вып. 11. С. 277-317.

12. Шабанова Ю. А. Мистический аспект антропологии Эдит Штайн: от феноменологии к томизму // Антропологические измерения философских исследований. 2016. № 10. С. 107-118.

13. Allwood J. Cognitive Science "Consciousness, Thought and Language" // Encyclopedia of Language and Linguistics. 2nd ed. Oxford: Elsevier, 2006. P. 44-53.

14. Allwood J. Linguistic Communication as Action and Cooperation. Göteborg: University of Göteborg, Department of Linguistics, 1976. 195 p.

15. Allwood J. Some comments on Wallace Chafe's "How Consciousness Shapes Language" // Pragmatics and Cognition. 1996. Vol. 4. № 1. P. 55-64.

16. Balding C. My animals and other family. L.: The Penguin Group, 2013. 258 p.

17. Baron-Cohen S. Mindblindness: An Essay on Autism and Theory of Mind. Cambridge, Mass.: The MIT Press, $1995.198 \mathrm{p}$.

18. Berry D. M., Kamsties E., Krieger M. M. From contract drafting to software specification: Linguistic sources of ambiguity [Электронный ресурс]. URL: https://www.researchgate.net/publication/228861133_From_Contract_ Drafting_to_Software_Specification_Linguistic_Sources_of_Ambiguity (дата обращения: 14.12.2020).

19. Chafe W. Discourse, Consciousness, and Time: The Flow and Displacement of Conscious Experience in Speaking and Writing. Chicago: The University of Chicago Press, 1994. 392 p.

20. Davis M. H. Empathy: A social psychological approach. Madison, WI: Brown and Benchmark, 1994. 271 p.

21. Delacourt G. La liste de mes envies. P.: Première édition février, 2012. 186 p.

22. Edwards D. Discourse and Cognition. L.: SAGE Publications, 1997. 368 p.

23. Eysenck S. B. G. Impulsive and antisocial behavior in children // Current Psychological Research. 1981. Vol. 1. P. 31-37.

24. Fuster J. M. Cortex and Mind: Unifying Cognition. Oxford: Oxford University Press, 2003. 294 p.

25. Geeraerts D. Empathic Viewpoint and Intersubjective Ambiguity // Наука без границ: синергия теорий, методов и практик: материалы Международной научной конференции (28-30 октября 2020 г.) / отв. ред. О. К. Ирисханова. М.: МГЛУ, 2020. С. 12-13.

26. Geeraerts D. Second order empathy and irony [Электронный ресурс]. URL: https://sisu.ut.ee/sites/default/files/ proovin/files/geeraerts.pdf (дата обращения: 25.11.2020).

27. Happe F., Brownell H., Winner E. The getting of wisdom: Theory of Mind in old age // Developmental Psychology. 1998. Vol. 34. № 2. P. 358-362.

28. https://dictionary.cambridge.org/ambiguity (дата обращения: 16.01.2021).

29. https://www.merriam-webster.com/dictionary/ambiguity (дата обращения: 16.01.2021).

30. Iacoboni M. Understanding others: Imitation, language, empathy // Perspectives on imitation: From cognitive neuroscience to social science / ed. by S. Hurley, N. Chater. Cambridge, MA: MIT Press, 2005. P. 77-99. 
31. Kuno S. Functional syntax: Anaphora, discourse, empathy. Chicago: University of Chicago, 1987. 320 p.

32. Martinovski B., Marsella S. Theory of Mind and Coping in Discourse // Proceedings of Artificial Intelligence and the Simulation of Behavior (AISB) Symposia on Mind-Minding Agents. Hatfield, U.K.: University of Hertfordshire, 2005. P. 48-51.

33. Munro A. Too much happiness. L.: Vintage, 2010. $312 \mathrm{p}$.

34. Rizzolatti G., Craighero L. The Mirror-Neuron System // Annual Review of Neuroscience. 2004. Vol. 27. P. $169-192$.

35. Schmitt É. E. La Rêveuse d'Ostende. P.: Albin Michel, 2009. 324 p.

36. Stephan W. G., Finlay K. The Role of Empathy in Improving Intergroup Relations // Journal of Social Issues. 1999. Vol. 55. № 4. P. 729-743.

37. Thompson E. Empathy and human experience // Science, Religion, and the Human Experience. 2005 . № 27. P. 261-287.

\section{Информация об авторах | Author information}

RU Шевелева Марина Сергеевна ${ }^{1}$

${ }^{1}$ Пятигорский государственный университет

EN Sheveleva Marina Sergeevna ${ }^{1}$

${ }^{1}$ Pyatigorsk State University

${ }^{1}$ wr08@mail.ru

\section{Информация о статье | About this article}

Дата поступления рукописи (received): 19.12.2020; опубликовано (published): 26.02.2021.

Ключевые слова (keywords): первичная/вторичная эмпатия; интерсубъектная коммуникация; амбигуентность; концептуализатор «говорящий»/«слушающий»; прагмасемантика; first-order/second-order empathy; intersubjective communication; ambiguity; conceptualiser “speaker/listener”; pragmasemantics. 